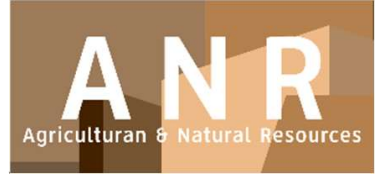

PAPER - OPEN ACCESS

Simbiosis Fungi Mikoriza Arbuskula Dengan Tumbuhan Adaptif Pada Lahan Pascatambang Emas

$\begin{array}{ll}\text { Author } & : \text { Faisal Danu Tuheteru } \\ \text { DOI } & : 10.32734 / \text { anr.v3i1.835 } \\ \text { Electronic ISSN } & : 2654-7023 \\ \text { Print ISSN } & : 2654-7015\end{array}$

Volume 3 Issue 1 - 2020 TALENTA Conference Series: Agriculturan \& Natural Resource (ANR)

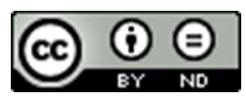

This work is licensed under a Creative Commons Attribution-NoDerivatives 4.0 International License.

Published under licence by TALENTA Publisher, Universitas Sumatera Utara

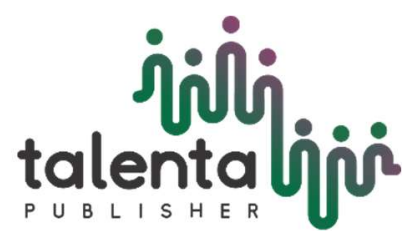




\title{
jibiti

\section{Simbiosis Fungi Mikoriza Arbuskula Dengan Tumbuhan Adaptif Pada Lahan Pascatambang Emas}

\author{
Faisal Danu Tuheteru ${ }^{\mathrm{a}}$, Husna $^{\mathrm{a}}$, Albasri ${ }^{\mathrm{a}}$ \\ ${ }^{1}$ Jurusan Kehutanan, Fakultas Kehutanan dan Ilmu Lingkungan, Universitas Halu Oleo Kendari, Sulawesi Tenggara. 93121, Indonesia
} fdtuheteru1978@gmail.com

\begin{abstract}
Abstrak
Fungi Mikoriza Arbuskula (FMA) merupakan fungi tanah yang dapat mengakselerasi suksesi vegetasi pada lahan-lahan rusak dan terdegradasi. Kehadiran tumbuhan adaptif di lahan-lahan pascatambang didukung oleh keberadaan FMA dalam tanah. Simbiosis FMA dengan perakaran tumbuhan adaptif masih terbatas di lahan pascatambang emas. Studi ini dilakukan pada lahan pasacatambang emas, Kabupaten Bombana, Sulawesi Tenggara pada Bulan April-Mei 2019. Sampel akar setiap tumbuhan diambil kemudian dicuci bersih. Akar-akar diwarnai menggunakan trypan blue $0.05 \%$. Hasil riset menujukkan bahwa struktur FMA mengkolonisasi perakaran 13 jenis tumbuhan adaptif. Struktur FMA tersebut adalah hifa internal, hifa eksternal, vesikula dan hifa coil. Rata-rata kolonisasi adalah 80,54 \% dengan kisaran 25-92\%. Jenis Eupatorium odoratum memiliki kolonisasi tertinggi yakni 92,59\%. Kolonisasi FMA pada perakaran tumbuhan adaptif menunjukkan bahwa keberadaan FMA sangat vital atau memegang peran penting bagi keberlangsungan hidup tumbuhan adaptif pada lahan pascatambang emas.
\end{abstract}

Kata Kunci: Hifa internal; simbiosis fungi mikoriza arbuskula; suksesi; Sulawesi Tenggara

\section{Pendahuluan}

Fungi mikroriza Arbuskula (FMA) merupakan jenis fungi dari Gloromycota yang bersimbiosis dengan $97 \%$ family tanaman darat pada beragam eksosistem [1]. Simbiosis ini bersifat mutualisme atau saling menguntungkan. FMA memperoleh sumber energi dari tanaman melalui eksudat akar hasil fotosintesis tanaman. FMA membantu keberhasilan hidup dan pertumbuhan tumbuhan melalui serapan hara dan air, serta melindungi tanaman dari cekaman lingkungan biotik dan abiotik [2]-[4]. Selain itu, FMA juga memfasilitasi suskesi vegetasi pada lahan atau hutan yang rusak. Salah satu lahan terdegradasi adalah lahan pascatambang emas

Simbiosis FMA dengan tumbuhan pioner pada lahan pascatambang emas di Indonesia telah dilaporkan. FMA bersimbiosis dengan vegetasi pada lahan tailing emas di Timika Papua [5], Lombok NTB [6] dan Mandailing Natal Sumatera Utara [7] juga di Afrika Selatan [8]. Studi yang sama di lahan pascatambang emas di wilayah Sulawesi Tenggara belum dilakukan. Beberapa jenis tumbuhan yang dilaporkan terkolonisasi FMA diantaranya Duabanga moluccana, Paraserianthes falcataria, and Erythrina orientalis, Asclepias fruticosa L., Asparagus laricinus, Cynodon dactylon, Ficus adenosperma, Brachiaria sp, Amomum sp., Bidens pilosa dan Musaenda frondosa [5],[6],[9]. Tujuan penelitian ini adalah mengetahui simbiosis FMA dengan perakaran tumbuhan pioneer di lahan tailing emas di PT. Panca Logam Makmur, Bombana Sulawesi Tenggara. Simbiosis yang dimaksud pada penelitian ini adalah kolonisasi FMA pada perkakaran tanaman yang ditandai dengan struktur FMA di akar. 


\section{Metode Penelitian}

\subsection{Waktu dan Lokasi}

Penelitian ini telah dilaksanakan di lahan pascatambang emas rakyat di Kabupaten Bombana Provinsi Sulawesi Tenggara pada bulan April-Mei 2019. Pengamatan kolonisasi akar dilakukan di Laboratorium Asosiasi Mikoriza Indonesia Cabang Sulawesi Tenggara, Kendari. Lokasi penelitian disajikan pada Gambar 1.

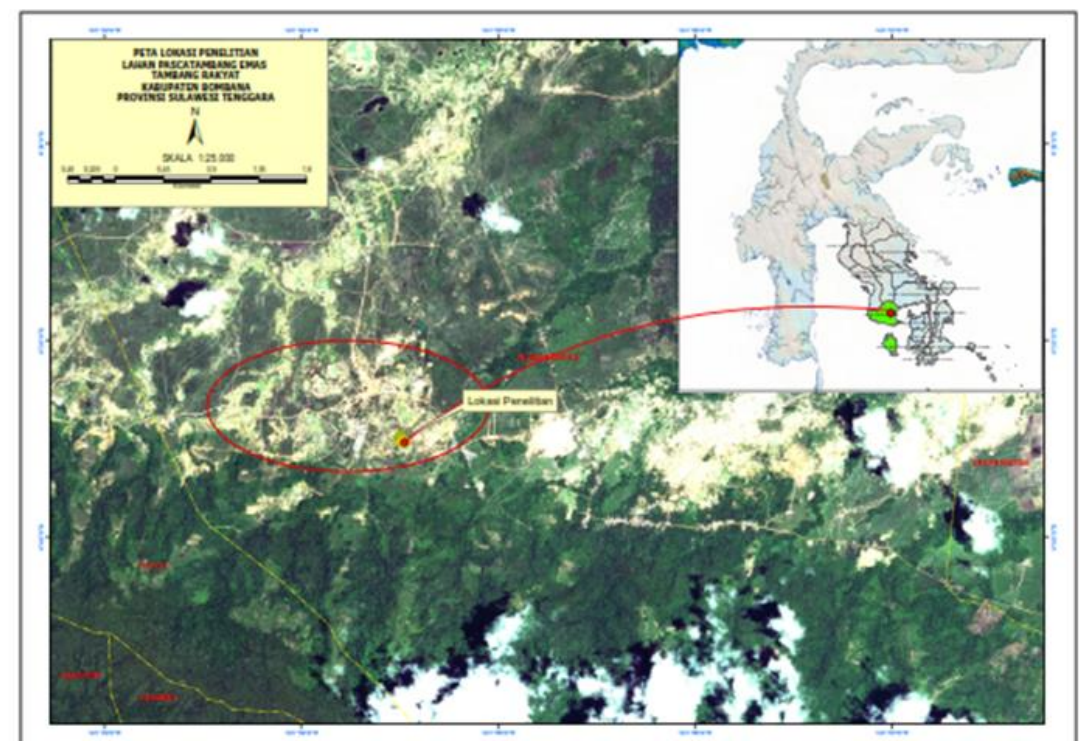

Gambar 1. Lokasi pengambilan sampel akar

\subsection{Sampling dan Persiapan Material Akar}

Sampel akar diambil dari 13 tumbuhan adaptif yang berada di tailing emas PT. Panca Logam Makmur, Kabupaten Bombana Provinsi Sulawesi Tenggara. Setiap contoh akar dari masing-masing tumbuhan dimasukkan ke tabung film yang berisi alkohol 70\% dan diberi nama tumbuhan setiap titik atau plot.

\subsection{Kolonisasi FMA}

Sampel akar dibersihkan dan diawetkan dalam larutan alkohol 70\%. Kolonisasi FMA dilakukan menurut metode Brundrett et al. 1996 menggunakan triphan blue. Kolonisasi FMA pada akar dihitung dengan rumus : [ $\Sigma$ bid pandang bermikoriza/ $\Sigma$ total bidang pandang yang diamati] x $100 \%$ [10].

\section{Hasil dan Pembahasan}

FMA mengkolonisasi perakaran 13 jenis tumbuhan adaptif pada lahan pascatambang emas di Bombana, Sulawesi Tenggara. Struktur FMA yang ditemukan di perakaran tumbuhan adalah hifa internal> hifa coil > vesikula>hifa eksternal (Tabel 1). Rata-rata kolonisasi adalah 80,54\% dengan kisaran 25-92\%. Jenis Eupatorium odoratum memiliki kolonisasi tertinggi yakni 92,59\%. 
Tabel 1. Kolonisasi FMA dan proporsi struktur FMA pada perakaran tumbuhan pioneer lahan pascatambang emas

\begin{tabular}{|c|c|c|c|c|c|c|c|}
\hline \multirow{2}{*}{ No } & \multirow{2}{*}{ Jenis } & \multirow{2}{*}{ Kolonisasi (\%) } & \multicolumn{5}{|c|}{ Proporsi struktur FMA (\%) } \\
\hline & & & $\mathrm{HI}$ & $\mathrm{HE}$ & $\mathrm{VE}$ & AR & $\mathrm{HC}$ \\
\hline 1 & Paspalum conjugatum & 84.4 & 55.6 & 0.0 & 18.5 & 0.0 & 25.9 \\
\hline 2 & Colopogonium & 92.0 & 60.9 & 4.3 & 13.0 & 0.0 & 21.7 \\
\hline 3 & Leptodoa & 91.3 & 69.0 & 2.4 & 0.0 & 0.0 & 28.6 \\
\hline 4 & Polygala cinensis & 78.9 & 60.0 & 0.0 & 26.7 & 0.0 & 13.3 \\
\hline 5 & Melochia & 90.0 & 26.7 & 17.8 & 33.3 & 0.0 & 22.2 \\
\hline 6 & Lesspedeza sp. & 66.7 & 40.0 & 10.0 & 10.0 & 0.0 & 40.0 \\
\hline 7 & Eupatorium odoratum & 92.6 & 72.0 & 0.0 & 0.0 & 0.0 & 28.0 \\
\hline 8 & Phylantus urgatus & 87.0 & 60.0 & 5.0 & 15.0 & 0.0 & 20.0 \\
\hline 9 & Imperata cylindrica & 91.3 & 61.9 & 14.3 & 14.3 & 0.0 & 9.5 \\
\hline 10 & Sporobius & 25.0 & 100.0 & 0.0 & 0.0 & 0.0 & 0.0 \\
\hline 11 & Chyperus ratundus & 70.0 & 85.7 & 0.0 & 14.3 & 0.0 & 0.0 \\
\hline 12 & Mimosa pudica & 87.5 & 95.2 & 4.8 & 0.0 & 0.0 & 0.0 \\
\hline \multirow[t]{2}{*}{13} & Aeschynomene indica & 90.3 & 67.9 & 10.7 & 0.0 & 0.0 & 21.4 \\
\hline & & 80.5 & 65.8 & 5.3 & 11.2 & 0.0 & 17.7 \\
\hline
\end{tabular}

Secara umum, tumbuhan adaptif bersimbiosis dengan FMA dibuktikan dengan ditemukannya struktur FMA pada perakaran tumbuhan. Kolonisasi FMA pada perakaran tumbuhan adaptif menunjukkan bahwa keberadaan FMA sangat vital atau memegang peran penting bagi keberlangsungan hidup tumbuhan adaptif pada lahan pascatambang emas. Berbagai studi melaporkan bahwa keberadaan FMA dapat mengakselerasi suksesi vegetasi alami pada berbagai kondisi lahan pasca tambang emas di dunia diantaranya di Indonesia [5,6], dan Afrika Selatan [8]-[9]. [11] melaporkan bahwa FMA merupakan komponen penting dalam restorasi ekosistem hutan terdegradasi.

Penelitian ini sejalan dengan beberapa hasil studi di wilayah lain. [6] melaporkan bahwa Glomus aggregatum Glomus geosporum, dan Glomus mossaeae bersimbiosis dengan Duabanga moluccana, Paraserianthes falcataria, dan Erythrina orientalis di Kecamatan Sekotong-Lombok Barat. Akar Asclepias fruticosa L., dan Asparagus laricinus Burch merupakan kolonisasi tertinggi pada lahan revegetasi tailing emas dan uranium di Afrika Selatan [8] Akar rumput, Cynodon dactylon terkolonisasi FMA dan vesikula di akar sebagai tempat sequestrasi logam dan naucleotida [9]. FMA ditemukan pada tailing emas di Timika pada tumbuhan Ficus adenosperma, Brachiaria sp, Amomum sp., Bidens pilosa dan Musaenda frondosa [5].

Pada penelitian ini, struktur FMA yang umum ditemukan adalah hifa internal> hifa coil> vesikula>hifa eksternal. Setiap struktur FMA memiliki peran dan fungsi yang berbeda. Hifa internal berfungsi sebagai organ transfer hara dari hifa eksternal ke tanaman. Hifa eksternal berperan sebagai organ FMA yang menyerap unsur hara dan air yang dibutuhkan oleh tanaman. Selain itu, hifa ekternal juga dapat menjadi media untuk menyimpan logam berat sehingga tumbuhan tidak mengalami keracunan serta memperbaiki struktur tanah [12]-[13].

\section{Kesimpulan}

Tumbuhan adaptif lahan pascatambang emas di Kabupaten Bombana, Sulawesi Tenggara bersimbiosis dengan fungi mikoriza arbuskula yang dibuktikan dengan struktur FMA pada perakaran tumbuhan adaptif. 


\section{Ucapan Terima Kasih}

Penelitian ini didanai oleh Direktorat Riset dan Pengabdian Kepada Masyarakat Kementerian Riset, Teknologi dan Pendidikan Tinggi skim Penelitian Dasar Kompetitif Nasional Tahun 2019 (No. 513g/UN29.20/PPM/2019) Terima kasih juga penulis ucapkan kepada Pimpinan PT.Panca Logam Makmur, Bombana.

\section{Referensi}

[1] Smith S.E., Read D.J. (2008) "Mycorrhizal symbiosis”, New York, Academic Press

[2] Tuheteru F.D., Q.S Wu. (2017) “Arbuscular Mycorrhizal Fungi and Tolerance of Waterlogging Stress in Plants," in QS Wu (ed) Arbuscular Mycorrhizas and Stress Tolerance of Plants, Singapore, Springer

[3] Husna, F.D., Tuheteru, A. Arif (2017b) “Arbuscular mycorrhizal fungi and plant growth on serpentine soils”, in Wu QS (ed) Arbsucular mycorrhizas and stress tolerance of plants, Singapore, Springer

[4] Husna, F.D. Tuheteru, and A. Arif (2018) "Arbuscular Mycorrhizal Fungi Symbiosis and Conservation of Endangered Tropical Legume Trees", in B. Giri et al. (eds) Root Biology, Soil Biology 52, Germany, Springer

[5] Suharno, R.P., Sancayaningsih, E.S. Soetarto, R.S. Kasiamdari (2014) "Keberadaan fungi mikoriza arbuskula di kawasan tailing tambang emas Timika sebagai upaya rehabilitasi lahan ramah lingkungan." J. Manusia dan Lingkungan 21 (3): 295-303.

[6] Utomo W.H., Suntari R., Arfarita N., Suhartini, and Handayanto E. (2014) "Rehabilitation of artisanal small gold mining land in West Lombok, Indonesia: 3. Exploration of indigenous plant species and the associated mycorrhiza for phytomycoremediation of mercury contaminated soils." American-Eurasian Journal of Sustainable Agriculture 8 (1): 34-41.

[7] Delvian, Elfiati D., Hartini K.S., Sipayung J., Sihombing S. (2016) "Inventarisasi tumbuhan pionir dan fungi mikoriza potensial pada lahan bekas tambang untuk kegiatan reklamasi”, dalam Materi presentasi Seminar Nasional BKS-PTN Bidang Ilmu Pertanian Agustus 2016, Medan

[8] Straker C.J., Weiersbye I.M., Witkowski E.T.F. (2007) "Arbuscular mycorrhiza status of gold and uranium tailings and surrounding soils of South Africa's deep level gold mines: I. Root colonization and spore levels.” South African Journal of Botany 73: 218-225.

[9] Weiersbye I.M., C.J. Straker, W.J. Przybylowicz (1999) "Micro-PIXE mapping of elemental distribution in arbuscular mycorrhizal roots of the grass, Cynodon dactylon, from gold and uranium mine tailings." Nuclear Instruments and Methods in Physics Res. B 158: $335-343$.

[10] Brundrett M., Bougher N., Dell B., Grove T., Majalaczuk (1996) “Working with Mycorrhizas In Forestry and Agriculture”, Canberra, Australian Centre for International Agriculture Research

[11] Shah M.A. (2014) "Mycorrhizas: Novel dimensions in the changing world", New Delhi, Springer

[12] Rillig M.C., Lutgen E.R., Ramsey P.W., Klironomos J.N., Gannon, J.E. (2005) "Microbiota accompanying different arbuscular mycorrhizal fungal isolates influence soil aggregation." Pedobiologia 49: 251-259.

[13] Rillig M.C., Wright S.F., Eviner V. (2002) "The role of arbuscular mycorrhizal fungi and glomalin in soil aggregation: Comparing effects of five plant species." Plant and Soil 238: 325-333. 